\title{
Processo de trabalho e saúde dos trabalhadores na produção artesanal de carvão vegetal em Minas Gerais, Brasil
}

\author{
Labor process and workers' health in charcoal \\ production in Minas Gerais, Brazil
}

Elizabeth Costa Dias 1

Ada Ávila Assunção 1

Cláudio Bueno Guerra 2

Hugo Alejandro Cano Prais 1

\footnotetext{
1 Departamento de Medicina Preventiva e Social, Faculdade de Medicina, Universidade Federal de Minas Gerais. Av. Alfredo Balena 190, Belo Horizonte, $M G$ 30130-100, Brasil. bethdias@medicina.ufmg.br 2 Agência Terra. Rua Nicarágua 275/603, Belo Horizonte, $M G$ 30320-050, Brasil.
}

\begin{abstract}
This study is a tentative approach to the relationship between environmental and occupational health and development in a specific situation: charcoal production in the Jequitinhonha Valley, the poorest region in the State of Minas Gerais, Brazil. The study focuses on the labor process, involving heavy exploitation, hazardous working conditions, and extremely precarious living conditions. Working conditions and activities are described and related to the workers' health situation. Social policies and decisive participation by the various social stakeholders are necessary to change this reality.

Key words Charcoal; Child Labor; Occupational Health

Resumo $O$ processo de trabalho na produção artesanal de carvão vegetal e sua articulação com as condições de vida e saúde de trabalhadores carvoeiros foram estudados em um Município do Vale do Jequitinhonha, em Minas Gerais, enfocando os aspectos históricos e econômicos da atividade carvoeira na região, a situação de saúde da população e dos trabalhadores, em particular, com destaque para as crianças e adolescentes envolvidos nessa atividade. O estudo do processo de trabalho foi baseado na observação direta, análise ergonômica das fases de abastecimento $e$ retirada do carvão dos fornos, entrevistas com trabalhadores e encarregados da produção e elaboração do "mapa de risco" da atividade. Os resultados indicam a necessidade da integração das políticas sociais e intervenção técnica visando transformar a atual situação social, cultural e laboral relacionada à produção artesanal de carvão, considerada muito precária.

Palavras-chave Carvão Vegetal; Trabalho de Menores; Saúde Ocupacional
\end{abstract}




\section{Introdução}

A produção de carvão vegetal em escala comercial surgiu em Minas Gerais, em meados do século XIX, na região de Mariana e Ouro Preto, favorecida pela abundância de jazidas de minério de ferro e recursos florestais da Mata Atlântica. Em 1940, o Estado de Minas já respondia por $90 \%$ da produção de ferro gusa do país, posição consolidada nos anos 50, com a implantação do pólo siderúrgico do Vale do Aço. Na década de 70, Minas Gerais tornou-se o maior pólo siderúrgico a carvão vegetal do mundo.

$\mathrm{Na}$ atualidade, o faturamento anual na cadeia produtiva da siderurgia a carvão vegetal madeira-carvão-ferro gusa/ferro ligas-aços - é de aproximadamente quatro bilhões de dólares, arrecadando 600 milhões de dólares de impostos e empregando 120 mil pessoas. O Estado de Minas produz e consome cerca de $80 \%$ do carvão vegetal brasileiro. Estima-se que 30\% do carvão utilizado no país sejam produzidos valendo-se de matas nativas, especialmente o cerrado em um processo primitivo, devastador do ambiente e da saúde dos trabalhadores (ABRACAVE, 1997; Agência Terra, 1996).

A mudança na base energética dos alto-fornos nas grandes empresas siderúrgicas do Estado de Minas Gerais, pela substituição do carvão vegetal pelo mineral nas coquerias, a partir dos anos 90, tem acarretado repercussões sociais e econômicas importantes, gerando desemprego e tornando inúteis as florestas homogêneas de eucalipto, subsidiadas pelos órgãos governamentais.

Na cadeia produtiva do aço, estão presentes condições de trabalho muito distintas: de um lado, as siderúrgicas certificadas segundo as normas internacionais; de outro, a precariedade das carvoarias artesanais, com utilização intensiva e predatória dos recursos florestais, exploração do trabalho em condições subumanas, incluindo crianças e adolescentes, empregando tecnologia rudimentar. $\mathrm{O}$ rendimento térmico na conversão madeira-carvão vegetal continua baixíssimo, em torno de $50 \%$, com desperdício dos inúmeros subprodutos gerados na queima, como o alcatrão, ácido pirolenhoso e diversos gases que não são aproveitados (CETEC, 1992).

Os resultados apresentados a seguir resultam do projeto de investigação Trabalho Precoce na Atividade Carvoeira em Minas Gerais: Um Estudo de Caso dos Impactos sobre a Saúde das Crianças e Adolescentes e uma Proposta de Melhoria das Condições de Vida e Trabalho, apoiado pelo Conselho Nacional de Desenvolvimen- to Científico e Tecnológico (CNPq), Coordenação de Aperfeiçoamento de Pessoal de Nível Superior (CAPES), Ministério do Trabalho e Fundação Jorge Duprat Figueiredo de Segurança e Medicina do Trabalho (FUNDACENTRO). Foi realizado como contribuição ao esforço conjunto do governo e sociedade para conhecer a problemática do trabalho precoce no país e nela intervir. (Brasil, 1998; Ministério Público do Trabalho, 1995; MTb, 1996), envolvendo uma equipe multidisciplinar de professores, alunos e estagiários da Área Saúde \& Trabalho, Departamento de Medicina Preventiva e Social da Faculdade de Medicina da Universidade Federal de Minas Gerais (Dias et al., 1999). A questão básica que orientou o estudo pode ser traduzida por: Quais as principais condições de risco para a saúde presentes no processo de produção artesanal do carvão vegetal e seus possíveis efeitos sobre a saúde dos trabalhadores?

\section{Metodologia}

O estudo desenvolveu-se em um município do Vale do Jequitinhonha, uma das regiões reconhecidamente mais pobres do Estado de Minas Gerais. A atividade de produção do carvão é economicamente relevante na região e realizada, de modo complementar, por empresas de reflorestamento e produção de carvão, subsidiárias de grandes grupos siderúrgicos e por pequenos produtores, em regime familiar ou de "empreitada", pela queima da mata nativa (cerrado) e do eucalipto. Considerando os objetivos do trabalho, privilegiou-se a análise da produção artesanal de carvão vegetal nas "carvoarias volantes": sistema de empreitada familiar, com a participação de crianças e adolescentes. Os dados foram obtidos por meio de observação direta e de entrevistas com os trabalhadores ativos e afastados, individualmente e em grupo, elaboração de "histórias de vida", com ênfase na história ocupacional, além da escuta de autoridades da administração municipal, profissionais dos sistemas de saúde e educação do município e encarregados da produção nas empresas.

Os resultados permitiram a elaboração do fluxograma das fases e subfases da produção do carvão vegetal. Com base no fluxograma, foram estudadas as condições potenciais de risco para a saúde, relacionadas com o trabalho. Duas das atividades consideradas mais arriscadas ou penosas, as fases de abastecimento do forno e retirada do carvão, foram objeto de análise ergonômica. As observações sistemáticas foram realizadas por dois pesquisadores utili- 
zando lápis, papel e cronômetro para o registro do número e o tamanho de "toras" de madeira transportadas pelo trabalhador em uma dada fase do processo. O tamanho das "toras" foi classificado aleatoriamente em pequeno, médio e grande. Este procedimento permitiu colocar em evidência o esforço físico despendido durante a realização das tarefas.

Os problemas de saúde dos trabalhadores foram identificados mediante revisão da literatura técnica relacionada às condições de risco identificadas no estudo do processo de trabalho e do perfil de morbi-mortalidade da população do município, além das informações de óbitos registrados no Cartório de Registro Civil, no período de janeiro de 1997 a dezembro de 1998; do registro de atendimento ambulatorial pelo SUS no ano de 1997; dos resultados da avaliação nutricional de crianças menores de cinco anos, disponíveis nos arquivos do Sistema de Vigilância Alimentar e Nutricional (SISVAN); e entrevistas com as equipes de saúde envolvidas no Programa de Saúde da Família (PSF), com os trabalhadores, e professores da rede de ensino. Foi confeccionado o "mapa de risco da atividade", sendo as condições de risco para a saúde, potencialmente, existentes no ambiente das carvoarias representadas em uma escala constituída por círculos de cores e tamanhos variados, para facilitar a compreensão por parte dos trabalhadores, de acordo com a metodologia proposta por Oddone et al. (1986) e adaptada por Lima (1990). O exercício foi realizado com dois grupos de trabalhadores: um constituído por 25 adultos, homens e mulheres, e outro por vinte adolescentes do sexo masculino, com idades entre 10 e 17 anos.

\section{O processo de trabalho na produção artesanal de carvão vegetal}

Todos os sentidos do observador são tocados ao se aproximar de uma carvoaria. Em um local plano, escolhido por exigência do processo em meio à mata, depara-se com a fileira de fornos semelhantes a iglus envolvidos pela fumaça, cujo cheiro forte faz arder os olhos e impregna tudo e todos ao redor. Pilhas de madeira esperam a vez de ir para o forno e montes de carvão, às vezes, ainda fumegantes, pelo ensacamento. Os trabalhadores, geralmente seminus, têm o corpo coberto pela fuligem e deles, muitas vezes, somente se vêem os olhos e os dentes.

A maneira pela qual os carvoeiros organizam o trabalho é variável: individual e solitário, ou em duplas. As principais funções no proces- so são as de forneiro-carvoeiro e de carbonizador-barrelador. No sistema de produção familiar, as crianças desde muito cedo, aos quatro, cinco anos, quando começam a andar com mais desenvoltura, acompanham os pais, especialmente as mães, às carvoarias e "brincam" de ajudar a encher o forno. Em torno de seis a sete anos, algumas delas já conhecem todo o processo, e aos 12, 13 anos assumem todas as tarefas, sem distinção de sexo. As mulheres são, geralmente, poupadas de algumas tarefas como o esvaziamento do forno; porém, observaram-se adolescentes do sexo feminino e mulheres jovens desempenhando todas as funções, além de acumularem as responsabilidades pelas tarefas domésticas, caracterizando uma dupla jornada de trabalho.

Nas carvoarias volantes, os trabalhadores moram ou ficam alojados próximos aos fornos, em instalações improvisadas, cobertas por lonas, dormem em catres e não dispõem de condições mínimas de higiene e saneamento básico. É comum uma família e alguns agregados dividirem o trabalho e a moradia.

O fluxograma da produção do carvão vegetal está representado na Figura 1.

O processo compreende seis fases principais, que podem ser desdobradas em etapas ou subfases. A rigor, o plantio e o cultivo do eucalipto também devem ser considerados como fases do processo; todavia, não foram detalhados neste estudo, pois, naquele momento, não estavam sendo processados na região. Entretanto, muitos dos trabalhadores entrevistados participaram dessa fase e a descreveram como desconfortável e perigosa para a saúde, notadamente pelo uso indiscriminado de agrotóxicos, destacando o emprego de crianças.

\section{Corte e transporte da madeira}

De modo esquemático, o processo de produção de carvão se inicia com o corte da madeira da mata nativa ou de florestas homogêneas de eucalipto, utilizando ferramentas manuais como foice e machado, ou mecânicas como a moto-serra, dependendo dos recursos do empregador ou contratador do trabalho. Cortada a lenha, ela é "lerada", ou seja, os galhos são retirados deixando os troncos roliços e dispostos para secar e, assim, diminuir o seu peso. Após um intervalo de 15 a 30 dias, a lenha é "embraçada", formando feixes e transportada até próximo ao forno, com o auxílio de animais de tração pelos "muleteiros" ou do trator, dependendo do porte da carvoaria, e aí armazenada em pilhas. 
Figura 1

Fluxograma da produção de carvão vegetal.

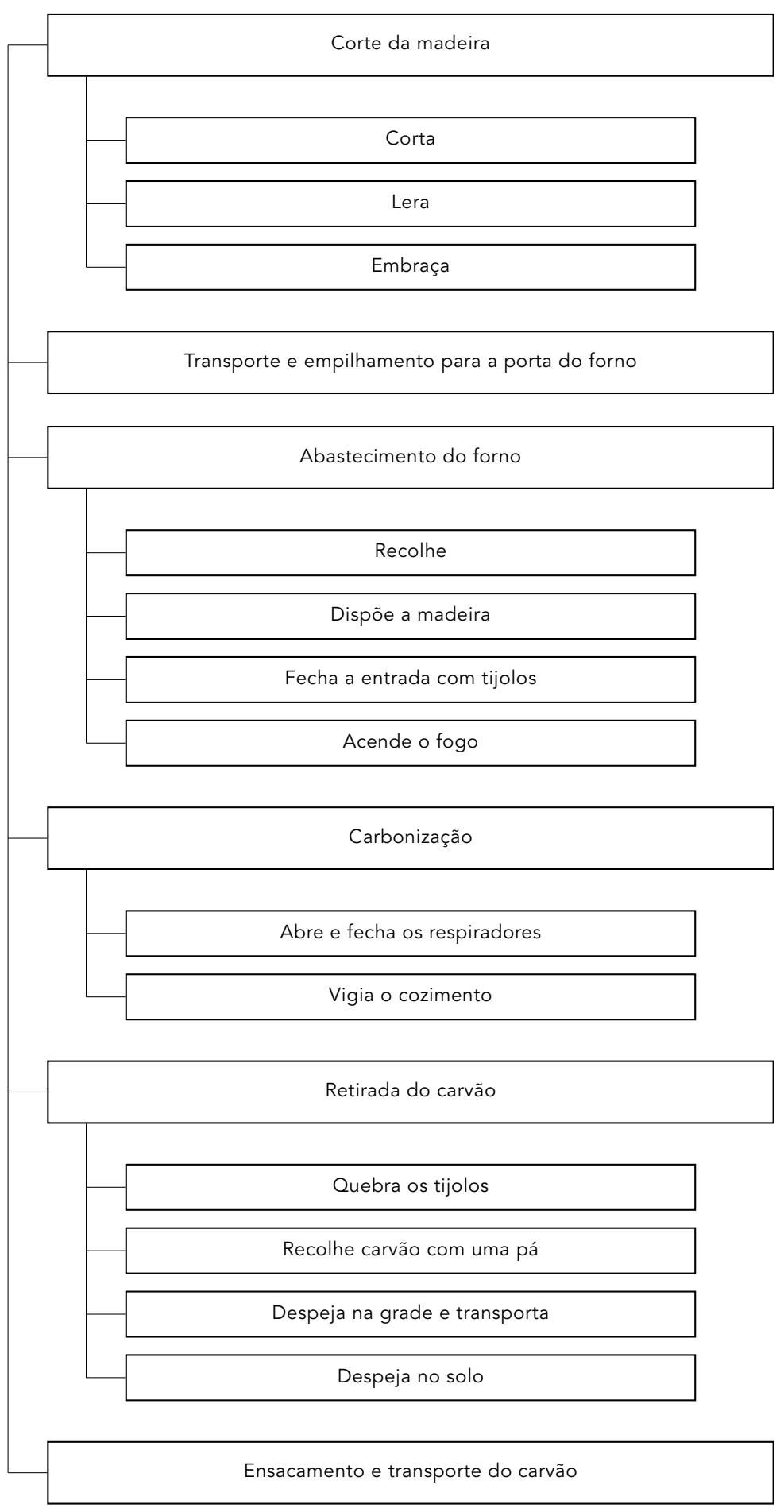

Abastecimento ou enchimento do forno

Para o abastecimento do forno, o trabalhador executa as seguintes atividades: (a) preparo do forno; (b) transporte manual da madeira estocada na área externa até a porta do forno; (c) transporte manual da madeira da porta do forno até o interior do mesmo; (d) enchimento do forno, organizando cuidadosamente as madeiras e; (e) fechamento do forno. No preparo do forno, o trabalhador limpa o interior do mesmo, retirando completamente o carvão produzido no processo anterior, utilizando garfo, pá, enxada, "raspelo" e rodo. A seguir, ele dispõe folhas secas pelo chão, preparando uma espécie de "tapete", para diminuir as perdas de calor para o solo. Continuando, as peças de madeira que estão estocadas na parte externa do forno são transportadas manualmente e deixadas perto da abertura ou "boca" do forno. Uma vez preenchida a abertura do forno, recomeça o transporte manual da madeira para o interior do mesmo. Dessa forma, o trabalhador transporta a mesma peça de madeira duas vezes.

A produtividade do forno depende do processo de enchimento. Se a carga é mal feita, a produção será menor do que a capacidade do forno, acarretando prejuízo. A presença de galhos ou folhas perturba a combustão "optima", alterando a qualidade do carvão. Durante a operação de enchimento do forno, o trabalhador assume posturas penosas. Ele sobe e permanece sobre a pilha de toras de madeira e as lança ao solo, o mais próximo possível da entrada do forno. À medida que o processo avança, e a "pilha" de madeira diminui, a retirada de uma "tora" faz com que as outras rolem pelo solo, aumentando o risco de acidentes. $\mathrm{O}$ empilhamento das "toras" na entrada do forno não é aleatório. Existe uma seleção cuidadosa das mesmas, e sua disposição é feita de modo a aproximá-las do espaço do forno que será preenchido naquele momento. O empilhamento prossegue até uma altura tal que permite apenas a passagem do trabalhador da área externa para o interior do forno. Ele se deita sobre as "toras" empilhadas e desliza sobre elas, chegando ao interior do forno e iniciando o processo de enchimento propriamente dito. Pela segunda vez, as "toras" são transportadas manualmente pelo trabalhador, respeitando uma organização minuciosa das madeiras, dispostas de forma centrípeta, ou seja, o espaço próximo às paredes é preenchido primeiro, avançando para o centro do forno. Uma vez no centro, a disposição obedecerá a outro padrão: da parte interna para a externa, no sentido da porta. Como o forno possui o formato de uma "oca", 
o trabalhador dispõe as "toras" em posição vertical para, em seguida, fazer o chamado "chapéu" do forno, colocando as "toras" de menor dimensão em sentido horizontal, sobre aquelas postas em sentido vertical. Este modo operatório tem o objetivo de garantir a qualidade do carvão exigida pelas siderúrgicas, que depende da combustão. Durante a observação sistemática realizada, o trabalhador transportou a madeira para a entrada do forno e em seguida para o interior do mesmo, seis vezes, até que o forno estivesse completamente abastecido.

A operação de abastecimento do forno apresenta exigências físicas e cognitivas para o trabalhador. As exigências físicas decorrem das condições de trabalho e do esforço muscular despendido. Os deslocamentos são numerosos e exigem movimentos coordenados dos membros superiores e inferiores; posturas penosas, com torção e flexão do tronco; movimentos repetitivos e uso de força para o transporte manual da carga. É importante destacar que o esforço físico se dá em condições de desconforto térmico, como será discutido mais adiante. A Tabela 1 mostra o peso transportado manualmente no enchimento de um forno e o tempo empregado para tal atividade. $\mathrm{O}$ trabalhador leva 41 minutos e 24 segundos para completar a tarefa, transportando cerca $7.357 \mathrm{~kg}$. O enchimento do forno é realizado em dois ciclos caracterizados pelo transporte da madeira até a porta e, a seguir, desta para o interior, transportando a mesma madeira duas vezes.

Nas situações analisadas, no conjunto das carvoeiras visitadas, não existe água potável disponível. Ao longo das observações sistemáticas, das primeiras horas do dia até o almoço, isto é, entre sete e onze horas da manhã, os trabalhadores que estavam abastecendo um forno não ingeriram água, apesar do esforço físico realizado e da intensa sudorese. Questionados a respeito, os trabalhadores responderam que preferem tomar água apenas no período da tarde. Posteriormente, revelaram a crença de que a ingestão de água, nas condições de exposição ao calor, poderia "cozinhar as tripas" ou provocar "constipação".

A dieta básica dos trabalhadores era composta basicamente de carboidratos, arroz, feijão e macarrão. Não havia banheiros para higiene pessoal e as condições de moradia eram, sempre, muito precárias.

Quanto às exigências cognitivas da operação de abastecimento do forno, observou-se que, na maioria dos casos analisados, os trabalhadores eram analfabetos e a aquisição dos conhecimentos necessários à realização das tarefas obtida empiricamente. Assim, o conheci-
Tabela 1

Número de "toras" transportadas em cada etapa do enchimento do forno, por peso aproximado da unidade e tempo de duração.

\begin{tabular}{llccc}
\hline Etapa & Duração & \multicolumn{3}{c}{ Número de toras } \\
\hline 1 & 7 min 4seg & 7 & 45 & 42 \\
2 & 7 min 95seg & 15 & 61 & 55 \\
3 & $3 \min 82 \mathrm{seg}$ & 13 & 69 & 56 \\
4 & $9 \min 21 \mathrm{seg}$ & 18 & 89 & 47 \\
5 & $6 \min 08 \mathrm{seg}$ & 12 & 60 & 12 \\
6 & 7 min 14seg & 24 & 83 & 19 \\
Total & 41 min 24seg & $1.780 \mathrm{~kg}$ & $4.884 \mathrm{~kg}$ & $693 \mathrm{~kg}$ \\
\hline
\end{tabular}

mento é incorporado por intermédio de sinais perceptivos em que os índices e os parâmetros utilizados pertencem à propriedade da matéria, como aspecto, forma, odor etc. Os trabalhadores sabem como fazer, ainda que não conheçam as propriedades físico-químicas da combustão. Este "saber-fazer", expressão traduzida do francês savoir-faire, é constituído por um conjunto de percepções, astúcias e truques adquiridos na prática, no aprender-fazendo. O trabalhador não possui conhecimentos formalizados e sistematizados, mas "incorpora” competências, não facilmente verbalizáveis, que ele mobiliza diante da variação das situações.

Entre as exigências cognitivas para a realização do abastecimento do forno está, por exemplo, o conhecimento específico sobre a disposição das "toras” no interior do mesmo. Durante o transporte das "toras" da parte externa para a porta do forno, o trabalhador seleciona-as de acordo com o espaço do forno que está sendo preenchido. Ele se orienta no espaço e no tempo, fazendo um planejamento que se expressa nas características das "toras" que são escolhidas. Por exemplo, é preciso separar aquelas mais curtas e mais largas para o "chapéu" do forno, deixando as mais compridas e estreitas para a base. Esta seleção é feita para preencher corretamente o forno, impedindo espaços livres entre uma "tora" e outra, que levam a uma supercombustão da madeira e interfere na qualidade do carvão. Existe um planejamento da ação para a seleção e disposição da "tora" mais adequada a um determinado lugar no forno, evitando a perda de calor e garantindo a qualidade do carvão. Finalizando, o forneiro ateia o fogo através de uma pequena abertura na porta, deixada especialmente para este fim, fechando o forno com tijolos e barrela, uma mistura aquosa de terra vermelha e água. 


\section{Carbonização}

A queima ou combustão da madeira dura geralmente três dias. Durante o cozimento da madeira, o carbonizador supervisiona o processo, no mínimo de hora em hora. Através da liberação e oclusão dos orifícios do forno, denominados "tatus" e "baianas", controla a entrada de oxigênio e dessa forma, a intensidade da combustão. Segundo os trabalhadores, esta operação é importante para garantir a qualidade do carvão. Para isso, consideram índices e parâmetros construídos na prática, como a cor e o volume de fumaça que sai pelos orifícios do forno. A fumaça de cor azul indica a conclusão do processo de cozimento da madeira. O principal cuidado do carbonizador é impedir que o forno "embale", produzindo um superaquecimento capaz de provocar a ruptura da cinta que sustenta a abóbada do forno, fazendo desmoronar toda a estrutura, com perda do produto ou carga.

Na experiência de Timóteo (1999), os carbonizadores consideram o seu cargo como "de confiança”, a função mais especializada, profissionalizada e de maior prestígio na atividade carvoeira. É uma tarefa penosa, vista por alguns trabalhadores como a "pior função" no carvão, por implicar trabalho noturno, já que o forno funciona ininterruptamente.

O barrelador tem a função de "sufocar" o forno, com o auxílio da barrela lançada sobre o forno para impedir a entrada de ar através de pequenas frestas e aberturas, que alimentam a combustão. Desta forma o forno é desligado e resfriado. O barrelador deve repetir este procedimento até que o fogo se extinga.

\section{Esvaziamento do forno}

ou retirada do carvão

Após o reconhecimento do "bom momento" e interrompida a combustão, o forno é deixado para esfriar, sendo então aberto e esvaziado. Os procedimentos adotados pelo trabalhador para a retirada do carvão são os seguintes: (a) quebra da parede do forno, no mesmo local onde foi fechado, para abri-lo; (b) transferência do carvão da parte interna para a "grade" colocada na porta do forno; (c) transporte da "grade" contendo o carvão, da porta do forno para a área externa, e derramamento deste no solo. Dependendo do ponto de "cozimento" do carvão, os trabalhadores lançam água sobre ele, para acelerar o processo de esfriamento e impedir a perda do produto. A tarefa é feita manualmente. Com a ajuda de um "garfo", que pesa cerca de quatro quilos, o trabalhador retira o carvão do forno, despejando-o na grade. Esta é um artefato metálico, medindo cerca de dois metros, fabricada com um trançar de arames, semelhante a uma gaiola, com duas alças em cada uma das extremidades, improvisadas com toretes. Quando a "grade" está cheia, o trabalhador pede a ajuda de um colega, e ambos, cada um segurando uma das alças da grade, transportam-na até uma área situada cerca de dois a três metros da porta do forno, despejando o carvão na terra para permitir o resfriamento, facilitar o transporte e ensacamento. A grade cheia pesa cerca de $50 \mathrm{~kg}$.

A análise da atividade mostra que a retirada do carvão é a fase mais crítica no que se refere à exposição a altas temperaturas e aos gases originados na combustão da madeira, sob exigência de esforços físicos importantes. Além disso, estão presentes riscos de acidentes como queimaduras. Em algumas situações, dependendo da urgência do pedido, do estado do "cozimento da madeira”, ou das exigências de qualidade do produto, o carvão é retirado ainda aquecido, aumentando a sobrecarga térmica e o risco de queimaduras corporais.

A atividade de esvaziamento do forno apresenta exigências físicas e cognitivas importantes. São necessários movimentos repetidos, com a pá ou o garfo, e adoção de posturas de flexão do tronco e suporte de cargas. A repetitividade da tarefa e as condições climáticas e de conforto desfavoráveis contribuem para a penosidade. A exposição combinada, ambiental e ocupacional, ao calor ou às altas temperaturas é significativa. O calor emitido para o meio ambiente de trabalho pelos fornos, no processo de carbonização da madeira, interage com o calor natural, importante na região e o calor corporal interno, ou seja, os deslocamentos numerosos e fatigantes levam ao aumento do metabolismo corporal e, como decorrência, ao aumento da produção interna de calor, explicando a intensa sudorese observada nos trabalhadores, durante a realização do trabalho. Na literatura especializada não foram encontrados estudos abordando a sobrecarga térmica na produção do carvão, em que o problema sobressai tanto na observação direta quanto na fala dos trabalhadores. Gripes e resfriados freqüentes são atribuídos pelos trabalhadores à exposição às diferenças de temperatura: elevada, próximo aos fornos, e baixa, no ambiente, nas madrugadas.

\section{Ensacamento e transporte}

A etapa de resfriamento do carvão exige um controle atento porque este pode entrar em combustão espontânea, causando a perda do 
produto. O carvão resfriado é ensacado e/ou colocado no caminhão para ser transportado e comercializado.

Em estudo realizado com trabalhadores de empresas de reflorestamento e produção de carvão no Vale do Aço, em Minas Gerais, Timóteo (1999:40) descreve a atividade de esvaziamento dos fornos como a pior tarefa do processo, recusada por muitos dos trabalhadores: " muitos entrevistados disseram que se este fosse o único serviço para se fazer, poderiam ser chamados de malandros, que eles não trabalhariam nunca na função”. Segundo o mesmo autor, os trabalhadores consideram o "pior no trabalho com o carvão”, o esforço físico em 53,1\% dos casos, seguido pela temperatura dentro do forno por $46,9 \%$, e pela poeira de carvão por $44,9 \%$ dos entrevistados.

Na opinião do engenheiro responsável por uma carvoaria industrial visitada, o carvão ideal apresenta as seguintes características: $72 \%$ de carbono fixo, $5 \%$ de umidade e resistência mecânica de modo que origine o mínimo possível de "finos". Para que se alcance esta especificação, o carvão deverá ser "carbonizado" por inteiro, garantindo suas propriedades de resistência. Isto exige que o trabalhador saiba analisar e interpretar os sinais da combustão da madeira; reconhecer o carvão de boa qualidade, consoante critérios informais como aspecto e cor, eliminando a madeira que não cozinhou ou "tiço"; retirar o carvão com a ajuda da pá para evitar quebra desnecessária e avaliar a necessidade de umedecer o carvão, e o momento para fazê-lo.

No conjunto, pode-se afirmar que, apesar da aparente simplicidade, cada uma das etapas do processo tem embutido um "saber fazer" essencial para garantir a qualidade do carvão. A carga de trabalho decorre das possibilidades que o sujeito/agente trabalhador terá, de acordo com as suas características individuais e aquelas da organização produtiva, para evitar a intensidade e a duração da exposição à nocividade das situações laborais, com repercussões importantes sobre suas condições de saúde e segurança (Echternacht, 2000).

\section{Principais impactos sobre a saúde dos trabalhadores carvoeiros segundo o estudo do processo de trabalho, os registros de saúde e entrevistas com os trabalhadores}

A compreensão mais recente sobre o processo saúde-doença dos trabalhadores rompe com a conceituação clássica dos acidentes do traba- lho e das doenças profissionais, incluindo formas variadas de adoecimento presentes na população em geral, que guardam distintas relações com o trabalho, e ultrapassam a abordagem “um risco-uma doença” (Mendes \& Dias, 1999).

O estudo do perfil de morbi-mortalidade da população do município estudado, na quase totalidade envolvida direta ou indiretamente com a produção de carvão, foi realizado seguindo os procedimentos anteriormente descritos. Dos 532 óbitos registrados no período assinalado, 58,6\% ocorreram em homens e $41,4 \%$ em mulheres. A média de vida foi de 54 anos para o sexo masculino e 59 para o sexo feminino, abaixo dos índices observados no Estado de Minas Gerais. Mais da metade dos óbitos ocorreram após os sessenta anos. Cerca de $20,5 \%$ dos óbitos ocorreram em adultos jovens, na faixa de 18 a 45 anos. Chama a atenção o fato de que cerca de $49,8 \%$ dos óbitos ocorreram sem assistência médica. Quanto às principais causas de morte, as doenças cardiovasculares lideram, destacando-se a miocardiopatia chagásica como a causa básica mais freqüente $(12,2 \%$ de todos os óbitos no período estudado). Em segundo lugar, aparecem as causas externas (suicídios, homicídios e acidentes) com $7,8 \%$ das ocorrências, sendo a maior prevalência dos acidentes entre os 18 e 45 anos de idade (55\% dos casos de acidentes), com uma média de idade de 36 anos. Para a mortalidade infantil, contribuíram as gastroenterites, em $24 \%$ dos casos, as doenças peri-natais, em $24 \%$, e as pneumonias em $18 \%$. Em $34 \%$ dos casos, a morte se deu por causa ignorada, revelando os baixos padrões de vida e assistência médica à população. É importante destacar que os dados de mortalidade infantil sofrem importante interferência da subnotificação dos nascimentos e dos óbitos, no município.

Entre os 7.566 pacientes atendidos pelo PSF, predominaram os diagnósticos de acometimento de vias aéreas superiores $(14,88 \%$ dos casos); parasitoses intestinais (10,78\%); hipertensão arterial $(10,47 \%)$; e as doenças do sistema músculo-esquelético e conjuntivo com $8,22 \%$ dos casos. Os atendimentos às gestantes representaram $8,91 \%$ das consultas. As condições nutricionais foram analisadas com base nas informações referentes a 676 crianças, em um universo de 917 cadastradas pelo SISVAN, observando-se uma taxa de desnutrição geral de 6,5\% (Z-score <-2; DP = desnutrição moderada + desnutrição grave). É interessante notar que a incidência de desnutrição moderada a grave foi de $25 \%$ entre filhos de carvoeiros e de $4,1 \%$ entre os filhos de lavradores. Também os casos mais graves de desnutrição foram obser- 
vados entre os filhos de carvoeiros, sugerindo que, a par da precariedade das condições de vida da população como um todo, ela é ainda pior entre os carvoeiros volantes.

Assim, os padrões de adoecimento e morte dessa população podem ser associados à pobreza e às más condições de vida, mas também às doenças crônico-degenerativas próprias da "modernidade". Também estão presentes os problemas de saúde relacionados com o trabalho, identificados na da elaboração do Mapa de Risco na Produção do Carvão (Dias et al., 1999).

Os riscos potenciais de traumatismos e picadas por animais peçonhentos, sobretudo cobras, escorpiões e aranhas estão presentes em todas as fases do processo. As falas e os desenhos das crianças reproduzem esta observação (R. B. Guerra, comunicação pessoal). O uso da moto-serra, além de ferimentos e traumatismos de gravidade variável, pode causar a perda auditiva induzida pelo ruído (PAIR), contribuir para os efeitos extra-auditivos do ruído, entre eles, a hipertensão arterial, problemas gastrointestinais, distúrbios de sono, além de doenças músculo-esqueléticas e vasculares decorrentes da exposição à vibração. $\mathrm{O}$ manuseio de machados e facões pode ocasionar lesões graves, em decorrência do despreparo do trabalhador, às vezes muito jovem, e do estado de conservação e adequação das ferramentas.

Nas fases de preparo e enchimento do forno, foram relatados acidentes envolvendo a queda das toras, atingindo os trabalhadores e provocando lesões de gravidade variável, de simples escoriações a traumatismos graves e fraturas. O esforço físico excessivo e o trabalho em posições forçadas, bem caracterizados pela análise ergonômica, estão presentes em todas as etapas do processo de trabalho. Como assinalado anteriormente, em 41 minutos e 24 segundos, o trabalhador transportou cerca de $7.357 \mathrm{~kg}$ para encher o forno, realizando movimentos repetitivos de torção e flexão do tronco.

A retirada do carvão do forno configura uma situação crítica, observando-se um sinergismo entre o esforço físico despendido, a repetitividade dos movimentos, as condições climáticas adversas, a exposição a altas temperaturas e a falta de condições mínimas de higiene e conforto. As queixas de lombalgias e problemas relacionados à coluna vertebral são muito freqüentes. Os problemas lombares aparecem como a segunda causa de demanda de consulta médica na rede de serviços de saúde, sendo expressivo o número de trabalhadores precocemente incapacitados para o trabalho. O esforço físico intenso e continuado, particularmente em jovens, é responsável pelo desenvolvi- mento de hérnias inguinais e escrotais, observação confirmada na literatura (Marcondes et al., 1992).

A fumaça que sai dos fornos irrita os olhos e as vias aéreas superiores, impregnando a pele e tudo que está ao redor. No processo de carbonização da madeira são produzidos subprodutos da pirólise e da combustão incompleta, como o ácido pirolenhoso, gases de combustão, Alcatrão, Metanol, Ácido Acético, Metanol, Acetona, Acetato de Metila, Piche, Dióxido de Carbono, Monóxido de Carbono, Metano, que escapam dos fornos através dos orifícios (Guerra, 1995) e podem provocar lesões das vias aéreas e intoxicação. Possíveis efeitos neurológicos e hematológicos, teratogênicos e carcinogênicos dessas substâncias, descritos na literatura necessitam ser mais bem investigados.

Resumidamente, o trabalho nas carvoarias expõe os trabalhadores a relações de trabalho injustas e instáveis, sem garantia dos direitos trabalhistas básicos, como jornada de trabalho definida, repouso semanal, férias, seguro social e de acidente do trabalho. As condições de trabalho são inadequadas, sem o mínimo conforto, os equipamentos e instrumentos de trabalho são arcaicos e/ou sem proteção, o trabalho é monótono e sob tensão, sobremaneira, na fase de "vigiar" o forno. As exigências de grande esforço físico, a exposição ao ruído e vibração pelo uso da moto-serra, à radiação solar excessiva, ao calor emitido pelos fornos, às substâncias químicas produzidas na combustão da madeira e à picada por animais peçonhentos são algumas das condições de risco para saúde identificadas no estudo. Considerando a fase de crescimento e desenvolvimento biológico e emocional das crianças e adolescentes trabalhadores, a exposição a essas condições de risco, sem a adoção de medidas de controle ou de segurança poderá comprometer sua saúde de modo irreversível (Assunção et al., 2001; Forastieri, 1997).

\section{À guisa de conclusão}

É difícil falar de conclusões em um estudo dessa natureza. Pode-se simplesmente propor que a atividade carvoeira nessa modalidade seja extinta, pois é intolerável que adolescentes ou crianças, homens e mulheres vivam e trabalhem sob as condições observadas. A consciência de que o Brasil exporta com o ferro gusa, a biodiversidade do Cerrado, madeira, o trabalho e a saúde dos trabalhadores, incluindo crianças e adolescentes deve nortear uma melhor distribuição dos lucros na cadeia produti- 
va do aço e reordenar os processos produtivos de modo a minimizar ou abolir algumas de suas conseqüências negativas, na direção de um desenvolvimento humano sustentável (Schaefer, 1994).

A realidade é complexa e convoca ao esforço de aprofundamento da questão e à busca de soluções. Entre os desafios está o de se conseguir melhorar as condições de trabalho, pela mecanização das fases mais agressivas, protegendo, contudo, o emprego e os trabalhadores (Zuchi, 2001). Quanto às crianças e adolescentes, para além da atuação de fiscalização e punição das transgressões da lei, são necessários

\section{Referências}

ABRACAVE (Associação Brasileira de Carvão Vegetal), 1997. Anuário Estatístico. Belo Horizonte: ABRACAVE.

AGÊNCIA TERRA, 1996. A Produção de Carvão Vegetal no Mato Grosso do Sul: Um Estudo de sua Dinâmica Sócio-Econômica e Ambiental. Belo Horizonte: Agência Terra/Fundo das Nações Unidas para a Infância.

ASSUNÇÃO, A. A.; PRAIS, H. A. C. \& DIAS, E. C., 2001. As incompatibilidades entre as solicitações das tarefas e as capacidades do organismo jovem: $\mathrm{O}$ caso da inserção de crianças e adolescentes na produção do carvão. In: XI Congresso da Associação Nacional de Medicina do Trabalho (ANAMT), Anais, CD-ROM. Belo Horizonte: ANAMT.

BRASIL, 1998. Trabalho Infantil no Brasil: Questões e Políticas. Brasília: Câmara de Política Social, Presidência da República.

CETEC (Centro Tecnológico de Minas Gerais), 1992. Programa de Pesquisa e Desenvolvimento em Biomassa e Siderurgia a Carvão Vegetal. Belo Horizonte: CETEC. (mimeo.)

DIAS, E. C.; ASSUNÇÃO, A. A.; GUERRA, C. B.; CURY, G. C.; BARROS, J. B.; GUERRA, R. B.; PRAIS, H. A. \& SALAZAR, A. L., 1999. Trabalho Precoce na Atividade Carvoeira em Minas Gerais: Um Estudo de Caso dos Impactos sobre a Saúde das Crianças e Adolescentes e uma Proposta de Melhoria das Condições de Vida e Trabalho. Relatório Final da Pesquisa. Belo Horizonte: Departamento de Medicina Preventiva e Social, Universidade Federal de Minas Gerais.

ECHTERNACHT, E. H. O., 2000. Sobre o Conceito de Carga de Trabalho. Belo Horizonte: Departamento de Engenharia de Produção, Universidade Federal de Minas Gerais. (mimeo.)

FORASTIERI, V., 1997. Children at Work: Health and Safety Risks. Geneva: International Labour Organization.

GUERRA, C. B., 1995. Meio Ambiente e Trabalho no "Mundo do Eucalipto". Belo Horizonte: Agência Terra.

LIMA, D. A., 1990. O Livro do Professor da CIPA. São Paulo: Fundação Jorge Duprat Figueiredo de Segurança e Medicina do Trabalho.

MARCONDES, E.; YUNES, J.; MASCARETTI, L. A. S.; LEONE, C. \& SCHVARTMAN, S., 1992. Os fatores programas específicos como o da "bolsa-escola” e outros similares, que permitam às famílias que vivem em situação de carência extrema "liberar" seus filhos para o estudo, dando-lhes outra perspectiva de vida, como assinalam Minayo-Gomez \& Meirelles (1997).

Além dessas e de outras iniciativas no campo da saúde e educação, são necessárias políticas públicas de mais longo alcance capazes de corrigir os efeitos deletérios do "desenvolvimento" da produção de carvão vegetal em Minas Gerais, que destroem o cerrado, restringem as alternativas econômicas para os pequenos agricultores e alimentam a exclusão social.

ambientais (Ecopediatria). In: Pediatria Básica (E. Marcondes, ed.), pp. 9-25, 8a Ed. São Paulo: Sarvier.

MENDES, R. \& DIAS, E., 1999. Saúde dos trabalhadores. In: Epidemiologia \& Saúde (Z. M. Rouquayrol \& N. Almeida Filho, org.), pp. 431-456, 5a Ed. Rio de Janeiro: Medsi.

MINAYO-GOMEZ, C. \& MEIRELLES, Z. V., 1997. Crianças e adolescentes trabalhadores: Um compromisso para a Saúde Coletiva. Cadernos de Saúde Pública, 13:135-140.

MINISTÉRIO PÚBLICO DO TRABALHO, 1995. Ações de Combate ao Trabalho Infantil na Atividade Carvoeira em Minas Gerais. Belo Horizonte: Delegacia Regional do Trabalho de Minas Gerais, Ministério Público do Trabalho. (mimeo.)

MTB (Ministério do Trabalho), 1996. Relatório da Oficina sobre os Impactos do Trabalho Precoce na Saúde de Crianças e Adolescentes. Brasília: Secretaria de Segurança e Saúde do Trabalho, MTb/ Fundação Jorge Duprat Figueiredo de Segurança e Medicina do Trabalho.

ODDONE, I.; MARRI, G.; GLORIA, S.; BRIANTE, G.; CHIATTELLA, M. \& RE, A., 1986. Ambiente de Trabalho: A Luta dos Trabalhadores pela Saúde. São Paulo: Editora Hucitec.

SCHAEFER, M., 1994. Salud, Medio Ambiente y Desarrollo: Enfoques para la Preparación de Estratégias a Nivel de Países para el Bienestar Humano segun la Agenda 21. Geneva: Organización Mundial de Salud. (mimeo.)

TIMÓTEO, G. M., 1999. Trabalhadores do Carvão: Um Estudo de Caso na Região do Vale do Aço. Belo Horizonte: Faculdade de Filosofia e Ciências Humanas, Universidade Federal de Minas Gerais.

ZUCHI, P. S., 2001. A Evolução na Produção de Carvão Vegetal e suas Repercussões na Produtividade e Qualidade do Carvão, nas Condições de Trabalho e no Meio Ambiente: Estudo Comparativo. Dissertação de Mestrado, Belo Horizonte: Departamento de Engenharia de Produção, Universidade Federal de Minas Gerais.

Recebido em 5 de dezembro de 2000

Versão final reapresentada em 5 de junho de 2001

Aprovado em 9 de outubro de 2001 